\title{
A LOW COST POTENTIOSTAT DEVICE FOR MONITORING AQUEOUS SOLUTION
}

\author{
S. N. H. Umar ${ }^{1 *}$, E. A. Bakar ${ }^{1}$, N. M. Kamaruddin ${ }^{1}$ and N. Uchiyama ${ }^{2}$ \\ ${ }^{1}$ School of Aerospace Engineering, \\ Universiti Sains Malaysia, \\ *Email: snhanisahumar@gmail.com \\ ${ }^{2}$ Department of Mechanical Engineering, \\ Toyohashi University of Technology, \\ Aichi, Japan.
}

\begin{abstract}
This study developed a new design of a low cost potentiostat circuit device. This device is an alternative electrochemical instrument applied for monitoring heavy metal ion in environmental water. It was developed to alleviate the cost burden of equipment procurement and due to the requirement for in-situ application since the existing commercialize devices are bulky and expensive. The main component of the device consist of electronics configuration of operational amplifier. The device was first modelled and simulated to acquire the design parameters and performance. The potential control algorithm was developed on open-source microcontroller platform. A dummy cell was used to validate the capabilities of the device.
\end{abstract}

Keywords: Potentiostat, Operational amplifier, Electrochemical, Electronics configuration.

\section{INTRODUCTION}

Water pollution is a serious threat to global health [1]. Heavy metal ions (HMI) especially lead $(\mathrm{Pb})$, cadmium $(\mathrm{Cd})$, mercury $(\mathrm{Hg})$, chromium $(\mathrm{Cr})$ and arsenic $(\mathrm{As})$ are highly toxic even in small doses [2]. Industrial activities are the main source of HMI [3]. These HMI are not biodegradable and have a tendency to accumulate in living organisms, causing various diseases and disorders to the nervous, immune, reproductive and gastrointestinal systems [2]. Thus, detection of HMI and determining their quantities is a paramount importance.

Conventional HMI detection technique such as spectroscopic is accurate, but costly, bulky, time consuming and require a well-trained analyst [4], [5]. An electrochemical technique is a reliable alternative to spectroscopic and has gained more popularity as it is more economic, user-friendly, allow a simple procedures and suitable to fabricated on small circuit in the portable form for in-field applications [2].

A potentiostat is a crucial component as the electrochemical analysers. The main functions are to control the applied potential voltage for HMI excitation in solution and to measure the resulting current due to movement of electron in the solution [6]. For potential control process, three electrode system was used as the sensor electrodes; working electrode (WE), reference electrode (RE) and counter electrode (CE) [7]. The WE can be defined as the electrode whose potential is a function of the solution's concentration [8]. The RE maintain a constant voltage referred to the potential of the hydrogen electrode. Thus, no current is allowed to pass the RE. The CE served to 
complete the electric circuit and provided the information of the ion in term of current reading.

In order to analyse and process the information from sensor electrodes, potentiostat is used. Due to the available commercialize potentiostat are expensive, bulky and often exceed the practical needs, researchers tends to build its own using existing information [9]-[16]. Thus, the purpose of this study is to describe the development of a potentiostat device for the purposed of HMI detection.

\section{METHODOLOGY}

\section{Concept of Main Potentiostat}

The proposed potentiostat was designed for three electrode system which consist of electronics configuration mainly the operational amplifier and resistor. The potentiostat can be categories into six main components as shown in Figure 1. The potentiostat was first designed and simulate on MATLAB Simscape for design parameters and performance test.

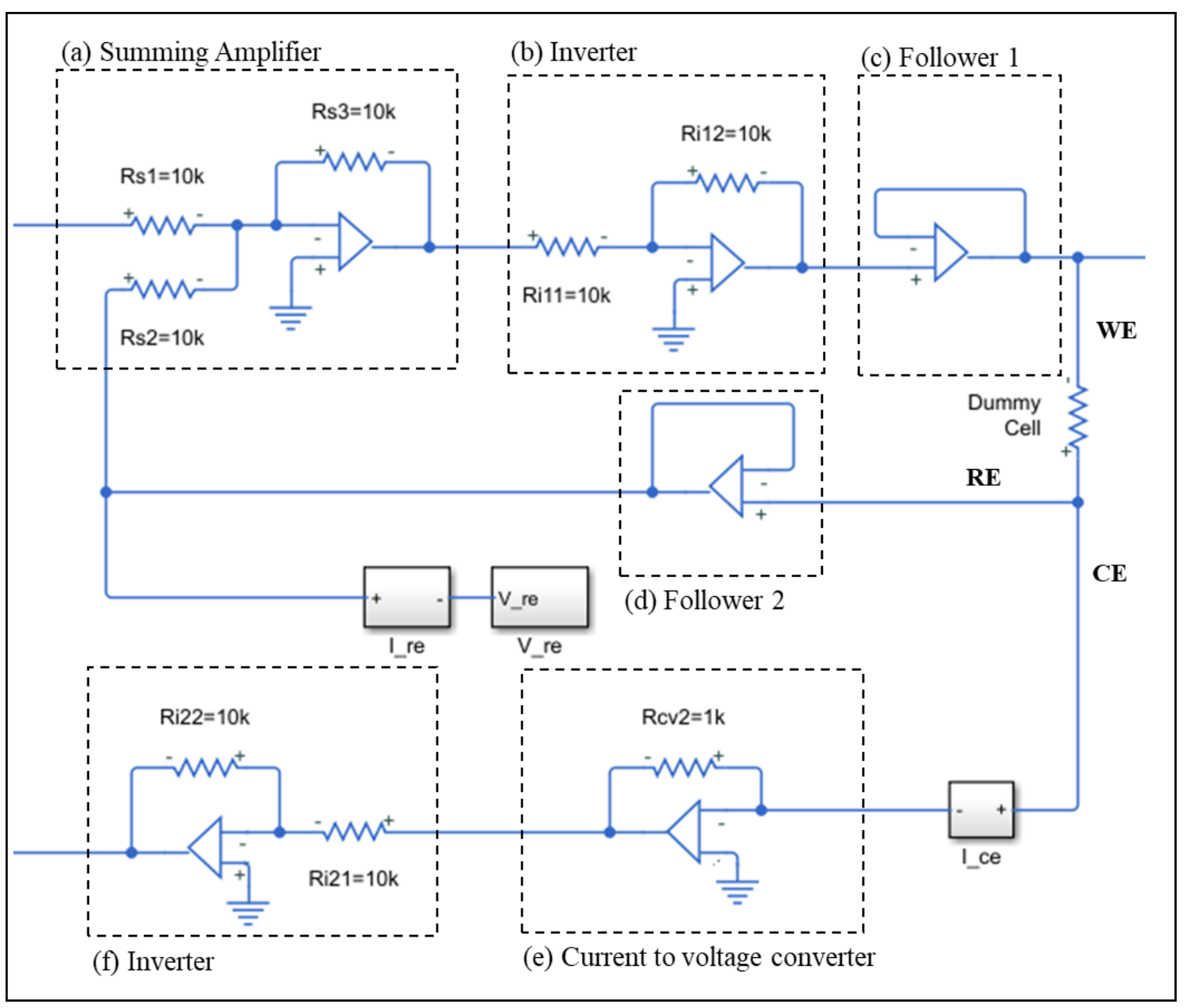

Figure 1 Potentiostat modelling.

Firstly, the applied potential voltage $V_{i n_{1}}$ passed through the summing amplifier. The main function of summing amplifier as in Figure 1(a), is to consider and provide the potential voltage, $V_{i n_{2}}$ sensed by RE as a feedback signal in potentiostat circuit. This is 
to ensure a sufficient excitation voltage supply at the WE due to the applied voltage at WE is always with respect to the RE. The general formulation for voltage summing is as below,

$$
V_{\text {out }}=-\left(\frac{R_{s 3}}{R_{s 1}} V_{\text {in }_{1}}+\frac{R_{s 3}}{R_{s_{2}}} V_{\text {in }_{2}}\right)
$$

Since $R_{S_{1}}=R_{S_{2}}=R_{S_{3}}=10 \mathrm{k} \Omega$, the output of summing amplifier can be written as,

$$
V_{\text {out }}=V_{i n_{1}}+V_{\text {in }}
$$

The output produced by voltage summing is in inverted polarity. Thus, an inverter as in Figure 1(b) is used to rectify the polarity. The general formulation of the inverter,

$$
V_{\text {out }}=-\frac{R_{i_{1}}}{R_{i_{2}}} V_{\text {in }}
$$

Since $R_{i_{1}}=R_{i_{2}}=10 \mathrm{k} \Omega$, the output of polarity inverter can be simplified as,

$$
V_{\text {out }}=-V_{\text {in }}
$$

A voltage follower as in Figure 1(c) and (d) provided a high input impedance to prevent significant current drawn that may lead to inaccurate potential voltage reading. The formulation of voltage follower can be written as,

$$
V_{\text {out }}=V_{\text {in }}
$$

The current signal from CE is measured using the transimpedance amplifier or current to voltage converter as in Figure 1(e). The formulation current to voltage converter is shown in Equation (6). The value of $R_{c v 2}$ determined the sensitivity range of the potentiostat. The inverter amplifier Figure 1(f) is cascade with transimpedance amplifier to rectify the output voltage polarity.

$$
V_{\text {out }}=i R_{c v 2}
$$

\section{Potentiostat Development}

The designed potentiostat was implemented on a breadboard using LM324N Operational Amplifier. The circuit arrangement is shown in Figure 2 consist of three parts, (a) an ATmega328P Arduino Uno microcontroller for signal generator, parameter control and data acquisition. The second part is (b) a digital and analog converter (DAC) including unipolar to bipolar converter (UBC) and bipolar to unipolar converter (BUC). The third part (c) is the main potentiostat circuit as described in Figure 1.

For hardware implementation, the DAC part was applied as a connector between the Arduino Microcontroller and the main potentiostat part. The detail description of DAC is shown in Figure 3. A low pass filter is used to convert the square wave signal generated by microcontroller pulse width modulation (PWM) into an analog voltage. The relation between PWM and desired analog voltage, $V_{i n}$ are stated in Equation (7). 


$$
V_{\text {in }}=\text { high voltage of PWM signal } \times \text { duty cycle }
$$

With the cut off frequency, $f_{c}$ of,

$$
f_{c}=\frac{1}{2 \pi R C}
$$

The PWM voltage of Arduino Uno board can only provide DAC voltage range from $0 \mathrm{~V}$ to $5 \mathrm{~V}$. Since electrochemical experiment usually required a potential range from $-1 \mathrm{~V}$ to $+1 \mathrm{~V}$, UBC is used as voltage mapping as shown in Error! Reference source not found. and the equation can be written as below,

$$
V_{\text {out }}=V_{\text {in }}\left(\frac{R_{2}}{R_{1}+R_{2}}\right)\left(1+\frac{R_{4}}{R_{4}}\right)-V_{2} \frac{R_{4}}{R_{3}}
$$

Substituted $R_{1}=20 \mathrm{k} \Omega, R_{2}=R_{3}=10 \mathrm{k} \Omega$, and $R_{4}=2 \mathrm{k} \Omega$, Equation (9) is simplified as,

$$
V_{\text {out }}=0.4 V_{\text {in }}-1
$$

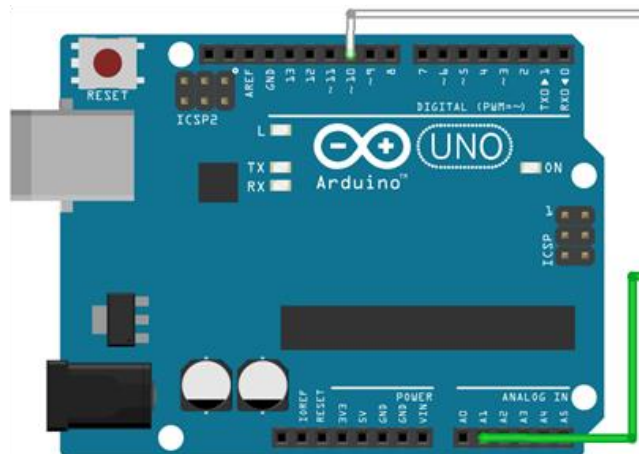

(a)

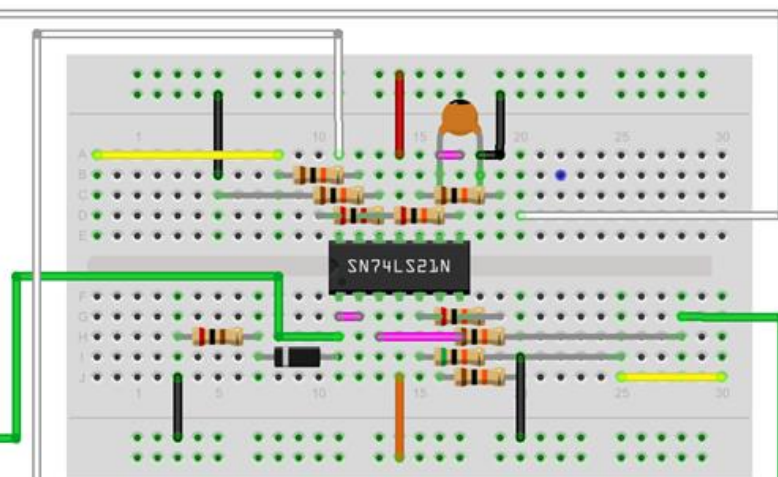

(b)

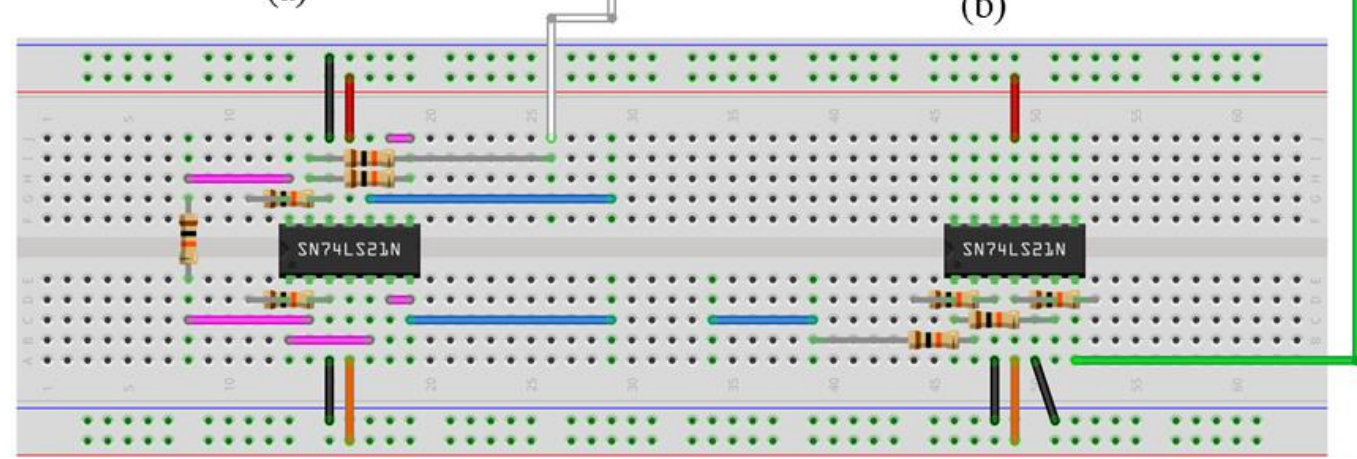

(c)

Figure 2 Potentiostat development board (a) microcontroller, (b) digital and analog converter and (c) main potentiostat circuit. 


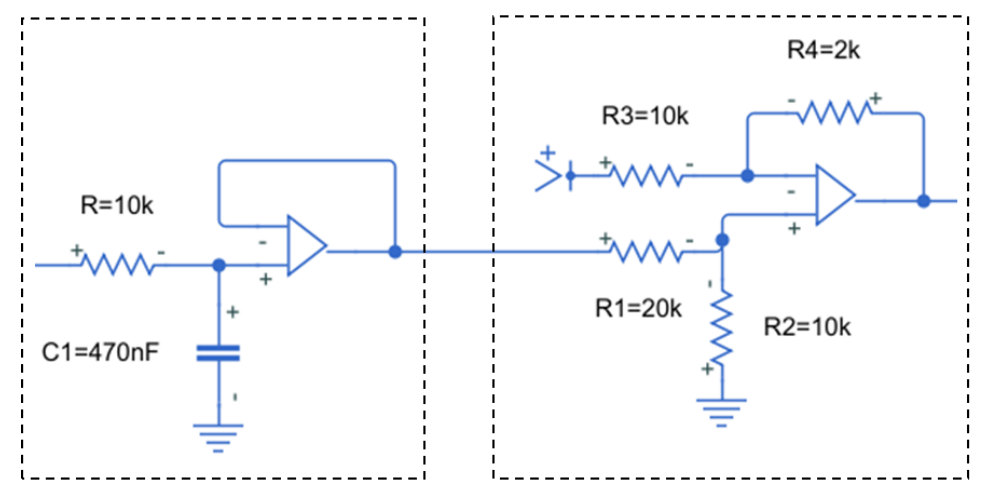

(a)

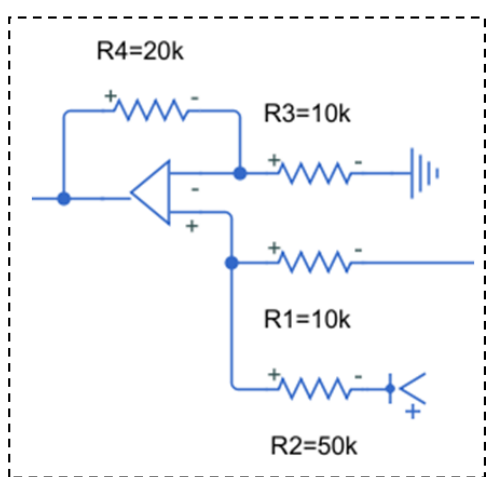

(c)

Figure 3 Components of digital and analog converter (a) low pass filter, (b) unipolar to bipolar converter and (c) bipolar to unipolar converter.

In Figure 4 shows the output of low pass filter indicated as Vin and the output of UBC indicated as Vout.

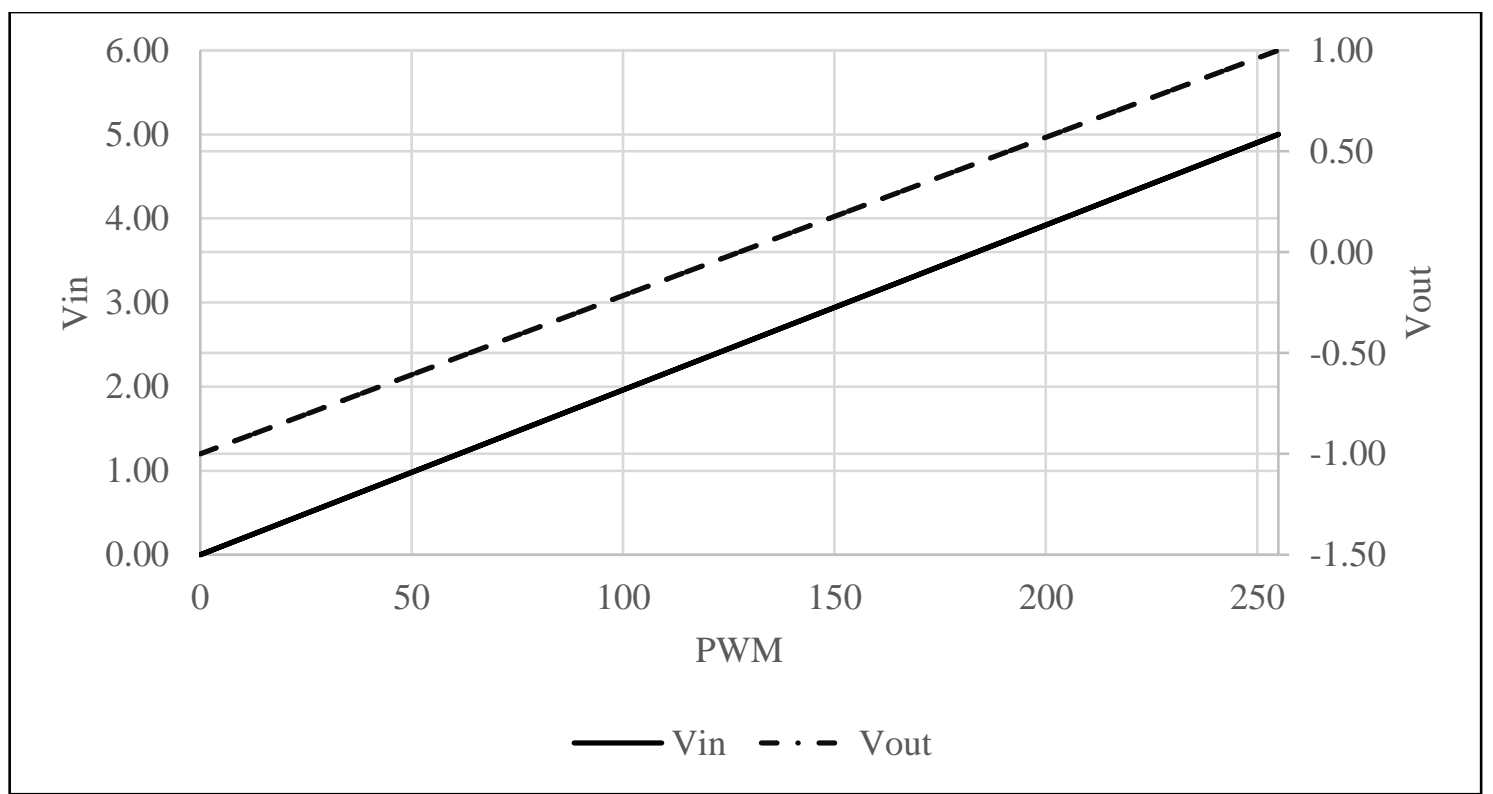

Figure 4 DAC and UBC output.

In order for microcontroller to analyse and process the signal from sensor electrodes, BUC as shown in Figure 3(c) is used to convert the voltage signal range (-1V to $+1 \mathrm{~V})$ from main potentiostat to microcontroller range $(0 \mathrm{~V}$ to $+5 \mathrm{~V})$. The formulation of the converter is shown below,

$$
V_{\text {out }}=\left(V_{\text {in }} \frac{R_{2}}{R_{1}+R_{2}}+V_{2} \frac{R_{1}}{R_{1}+R_{2}}\right)\left(1+\frac{R_{4}}{R_{3}}\right)
$$

Substitute resistance value, rewrite Equation (11) as,

$$
V_{\text {out }}=2.5\left(V_{\text {in }}+1\right)
$$




\section{RESULTS AND DISCUSSION}

The capability of the potentiostat device was verified using a dummy cell. The dummy cell is a device replicated the dynamics of electro-analytical cells using passive electrical components such as resistors and capacitors in certain configurations. Linear sweep voltammetry was applied to evaluate the performance of the potentiostat device. Dummy cell of $1 \mathrm{k} \Omega, 2 \mathrm{k} \Omega$ and $10 \mathrm{k} \Omega$ were connected between WE and RE and CE.

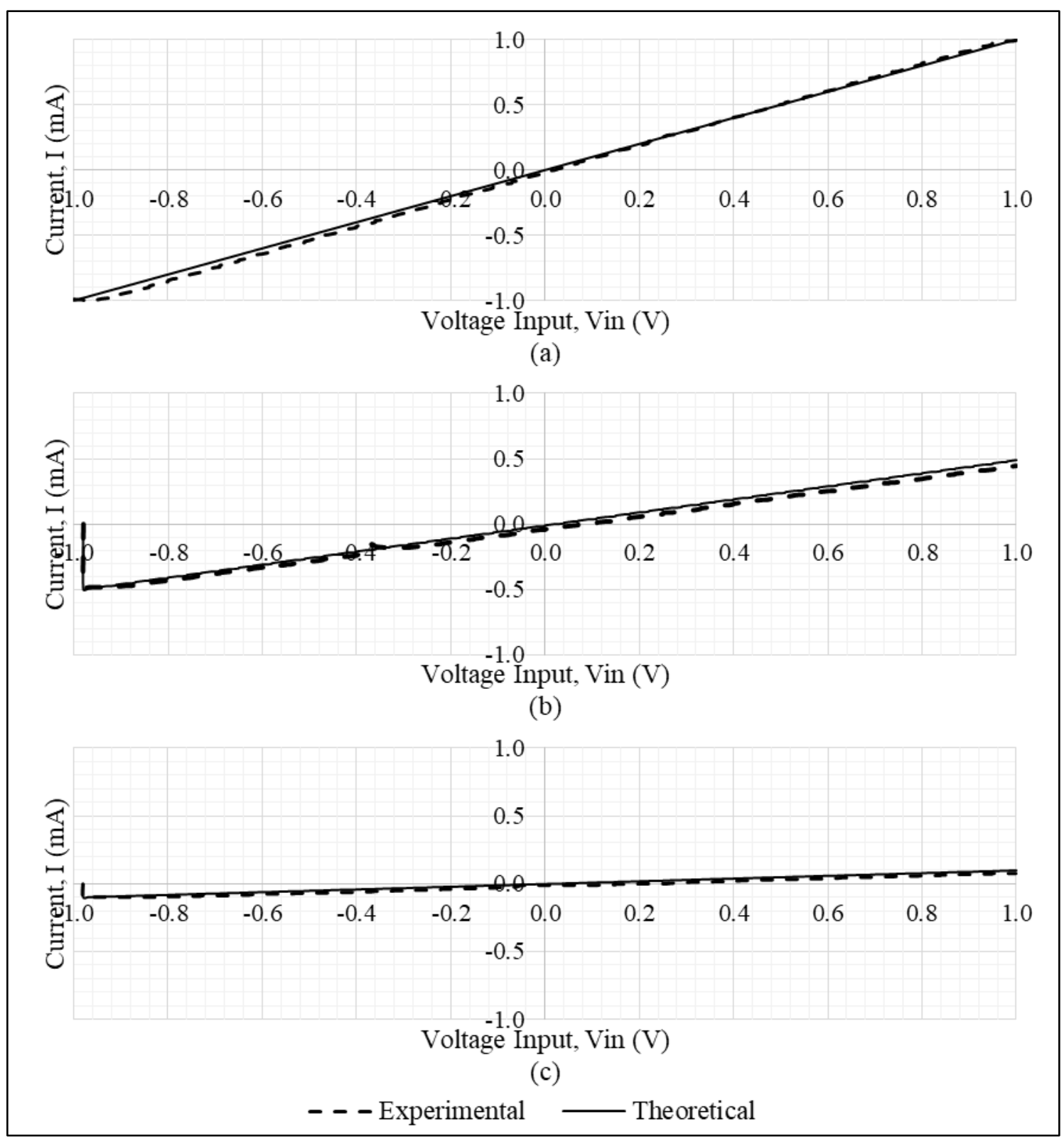

Figure 5 Resistor polarization curve using (a) $1 \mathrm{k} \Omega$ resistor, (b) $2 \mathrm{k} \Omega$ resistor and (c) $10 \mathrm{k} \Omega$ resistor.

When a potential is swapped between the leads of a resistor, the measured current can be calculated based on the apply voltage input, $V_{\text {in }}$ at the $\mathrm{WE}$ and is expected to show a linear response. As seen in Figure 5, the expected behaviour is observed. A similar trend was seen between experimental and theoretical. The polarization resistance was obtained as the inverse value of slop, $m=1 / R_{p}$ with $R_{p}=0.962 \mathrm{k} \Omega, 2.099 \mathrm{k} \Omega$ and $10.121 \mathrm{k} \Omega$ for 
dummy cell $1 \mathrm{k} \Omega, 2 \mathrm{k} \Omega$ and $10 \mathrm{k} \Omega$ respectively. These values were in a good agreement with the $10 \%$ tolerance resistor used. The mean error between experiment and theoretical is small up to $1.30 \mathrm{E}-05$ as shown in Table 1.

Table 1 Mean error of validation test.

Dummy validation test value, $\mathrm{R} \quad$ Voltage input, Vin $\quad$ Mean error, e

\begin{tabular}{cll}
\hline$R=1 k \Omega$ & from $-1 \mathrm{~V}$ to $+1 \mathrm{~V}$ & $2.41 \mathrm{E}-05$ \\
$R=2 k \Omega$ & from $-1 \mathrm{~V}$ to $+1 \mathrm{~V}$ & $2.95 \mathrm{E}-05$ \\
\hline$R=10 k \Omega$ & from $-1 \mathrm{~V}$ to $+1 \mathrm{~V}$ & $1.30 \mathrm{E}-05$
\end{tabular}

\section{CONCLUSION}

In this study, the low cost ( $<$ RM100) potentiostat device was developed using ATmega328P Arduino Uno microcontroller, LM324N operational amplifier, resistors and capacitor. Based on verification test, the designed potentiostat was capable to work as desire with similar trend and small mean error (up to 1.30E-05) between theoretical and experimental.

For further development study, it is highly recommend to improve in the following areas: (1) perform device validation using an actual electrochemical setup, (2) construction of the device using a custom etched printed circuit board and (3) higher portability for use in low-resource settings for researches and potential point-of-use care analysis.

\section{ACKNOWLEDGEMENTS}

The authors would like to acknowledge Universiti Sains Malaysia (USM) and Ministry of Education (MOE) for providing the financial assistance under RU Top-Down research grant (1001/PAERO/6740041) and awarding her USM Academic Staff Training Scheme (ASTS).

\section{REFERENCES}

[1] P. Wu, G. Vazquez, N. Mikstas, S. Krishnan, and U. Kim, "Aquasift: A low-cost, hand-held potentiostat for point-of-use electrochemical detection of contaminants in drinking water," 2017 IEEE Glob. Humanit. Technol. Conf., pp. 1-4, 2017.

[2] B. K. Bansod, T. Kumar, R. Thakur, S. Rana, and I. Singh, "A review on various electrochemical techniques for heavy metal ions detection with different sensing platforms," Biosens. Bioelectron., vol. 94, no. January, pp. 443-455, 2017.

[3] F. Fu and Q. Wang, "Removal of heavy metal ions from wastewaters: A review," J. Environ. Manage., vol. 92, no. 3, pp. 407-418, 2011.

[4] M. Nizar et al., "An Electroanalytical Instrument Equipped with Wireless Communication Network and Graphical User Interface for Real-time Monitoring Wastewater Status from Batik Industry," J. Mech. Eng. Vo l SI, vol. 4, no. 2, pp. 153-170, 2017.

[5] M. B. Gumpu, S. Sethuraman, U. M. Krishnan, and J. B. B. Rayappan, "A review on detection of heavy metal ions in water - An electrochemical approach," Sensors Actuators, B Chem., vol. 213, no. 2015, pp. 515-533, 2015.

[6] Ametek Scientific Instrument, "A Review of Techniques for Electrochemical 
Analysis," Princeton Applied Research. [Online]. Available: http://nanobioelectronics.weebly.com/uploads/3/8/8/6/38862535/review_of_tech niques_for_electrochemical_analysis.pdf.

[7] T. Arevalo-Ramirez, C. C. Torres, A. C. Rosero, and P. Espinoza-Montero, "Low cost potentiostat: Criteria and considerations for its design and construction," Proc. 2016 IEEE ANDESCON, ANDESCON 2016, 2017.

[8] D. Harvey, Modern Analytical Chemistry. 2000.

[9] G. N. Meloni, "Building a microcontroller based potentiostat: A inexpensive and versatile platform for teaching electrochemistry and instrumentation," J. Chem. Educ., vol. 93, no. 7, pp. 1320-1322, 2016.

[10] A. Ainla, M. P. S. Mousavi, M. Tsaloglou, J. Redston, G. Bell, and M. T. Ferna, "Open-Source Potentiostat for Wireless Electrochemical Detection with Smartphones," Anal. Chem., 2018.

[11] C. Y. Huang, H. T. Huang, and R. T. Yuan, "Design of a portable mini potentiostat for electrochemical biosensors," Proc. 2017 IEEE 2nd Adv. Inf. Technol. Electron. Autom. Control Conf. IAEAC 2017, pp. 200-203, 2017.

[12] D. L. Agulto, J. C. A. Guinto, L. K. G. Palomo, J. F. Villaverde, and M. A. C. Fabro, "Design of Microcontroller-based Potentiostat with Performance Validation using Auto Lab Eco Chemie Dummy Cell 2."

[13] A. A. Rowe et al., "Cheapstat: An open-source, 'do-it-yourself' potentiostat for analytical and educational applications," PLoS One, vol. 6, no. 9, p. 7, 2011.

[14] M. D. M. M. Dryden and A. R. Wheeler, "DStat: A Versatile, Open-Source Potentiostat for Electroanalysis and Integration," PLoS One, vol. 10, no. 10, p. e0140349, Oct. 2015.

[15] K. Christidis, K. Gow, P. Robertson, and P. Pollard, "Intelligent potentiostat for identification of heavy metals in situ," Rev. Sci. Instrum., vol. 77, no. 1, pp. 1-4, 2006.

[16] P. Bezuidenhout, S. Smith, K. Land, and T. H. Joubert, "A low-cost potentiostat for point-of-need diagnostics," in 2017 IEEE AFRICON: Science, Technology and Innovation for Africa, AFRICON 2017, 2017, pp. 83-87. 